\title{
Study Outcome Measure Type Code
}

National Cancer Institute

\section{Source}

National Cancer Institute. Study Outcome Measure Type Code. NCI Thesaurus. Code C94095.

A coded value specifying the kind of study outcome measure. 